\title{
Evidence of Liver and Kidney Injuries Attributable To Oral Bromocriptine Methanesulfonate in Mice.
}

\author{
Adejoke Y. Onaolapo ${ }^{1}$, Olakunle J. Onaolapo ${ }^{2}$, Adewale Fisayo ${ }^{1}$, Ojo Toyosi ${ }^{1}$, \\ Asolo, Samson ${ }^{1}$, Aisida Olubukola ${ }^{1}$ \\ ${ }^{I}$ Department of Human Anatomy, Ladoke Akintola University of Technology, Ogbomoso, Oyo state, Nigeria. \\ ${ }^{2}$ Department of Pharmacology and Therapeutics, Ladoke Akintola University of Technology, Oshogbo, Osun \\ state, Nigeria. \\ Corresponding Author: Olakunle J. Onaolapo: Department of Pharmacology, Ladoke Akintola University of \\ Technology, Ogbomoso, Oyo state, Nigeria.
}

\begin{abstract}
As a sequel to a previous study examining behavioral effects of bromocriptine methanesulfonate, this study was to evaluate the effects of the same drug on the liver and kidneys of Swiss albino mice. Male mice weighing between 16- $20 \mathrm{~g}$ were assigned into three groups of ten mice each. First group received normal saline; the other two groups were given bromocriptine methanesulfonate at 2.5 and $5.0 \mathrm{mg} / \mathrm{kg} /$ day respectively, drug or vehicle was given daily using an oral cannula for a period of 30 days. Body weight was measured weekly, and at the end of the treatment period mice were sacrificed and the liver and right kidney dissected out and weighed following which sections of the liver and kidneys were prepared for histologic study. Data was analysed using one way ANOVA followed by the Student-Newman-Keul's test, results were expressed as mean \pm S.E.M. A dose dependent increase in relative liver and kidney weights were seen in the test groups. Test groups' histology also showed evidence of liver and kidney injury. The study concluded that at doses tested, bromocriptine has both hepatotoxic and nephrotoxic potential in mice.
\end{abstract}

Keywords: Bromocriptine Methanesulfonate, Hepatotoxicity, Nephrotoxicity.

\section{Introduction}

Bromocriptine, an ergot alkaloid derivative is related chemically to d-lysergic acid diethylamide (LSD), ergotamine, ergonovine and methylergonovine; it is a white or slightly colored fine crystalline powder and almost odorless. It mimics some of the actions of dopamine, although not readily metabolized as is dopamine. It is a sympatholytic dopamine D2 receptor agonist exerting an inhibitory effect on the turnover of serotonin in the central nervous system (1); it also acts as an inhibitor of prolactin secretion from the anterior pituitary gland by its effects on dopaminergic neurons in the tuberoinfundibular process.

Bromocriptine, following oral administration is rapidly absorbed appearing in the plasma within 10 minutes (2) and attaining maximum plasma concentrations reportedly in 1 to 1.5 hours. However, the oral absorption from the gastrointestinal tract is only approximately $28 \%$; in addition, it undergoes a significant firstpass metabolism in the liver, such that the oral bioavailability is only approximately $6 \%$ (3). 90 to $96 \%$ of it is bound to serum albumin and it has been observed that bromocriptine and its metabolites do not distribute appreciably in erythrocytes. The volume of distribution is approximately $3 \mathrm{~L} / \mathrm{kg}$. It is not known whether the drug distributes to breast milk or distributes to the fetus in pregnant women (4).

Metabolism of bromocriptine in the liver is by hydrolysis and isomerization to 2-bromolysergic acid and 2-bromoisolysergic acid and by hydroxylation and this is believed to be almost complete in that only its metabolites are excreted and none have been documented to have any pharmacological activity (5). The major route of excretion is in bile with about 70 to $85 \%$ of the drug excreted in feces through the bile within 5 days of a single oral dose. Only 2.5 to $7 \%$ of a dose is excreted in the urine as metabolites (6). The incidence of side effects following bromocriptine usage is quite high (69\%) (7). These adverse effects however vary from mild to moderate in degree, most of these side effects are documented as being dose related and seen more often with the higher doses, reduction in dose, followed in a few days by a more gradual increase, may alleviate many side-effects. (7). In humans, bromocriptine has been known to cause rarely acute liver injury (8-9) usually evident by a slight self limiting elevation in alanine transferase level that more often than not does not necessitate drug withdrawal. In the course of a recent study on the neurobehavioral effects of bromocriptine methanesulfonate (10), limb and tail swellings and subsequent non-traumatic amputations with increased morbidity and mortality were seen in groups that received bromocriptine, the weight of the liver and kidneys of these animals were also higher than those of controls. These observations necessitated a full evaluation of bromocriptine effects on liver and kidney microanatomy in healthy Swiss mice. 


\section{Materials and methods}

\subsection{Equipments and apparatus} and cotton wool.

Electronic precision balance, plastic animal cages, sterile disposable syringes (1, 5 and $10 \mathrm{mls}$ ), needles

\subsection{Reagents and drugs}

Normal saline, 5\% ethanol. Bromocriptine Tablets (Bromergon), (Lek Pharmaceuticals and Chemicals) (weighed, crushed and dissolved in a measured volume of isotonic saline to get desired concentration). Bromocriptine at 2.5 and $5.0 \mathrm{mg} / \mathrm{kg}$ was administered orally using a cannula.

\subsection{Animals}

Healthy adult male mice (Empire Breeders, Oshogbo, Osun State, Nigeria) weighing between 16 to 20 $\mathrm{g}$ were used. Mice were housed in plastic cages, and all animals had free access to food and water ad libitum. They were maintained under standard laboratory conditions. The experimental protocol was approved by the Animal Ethics Committee of the Ladoke Akintola University of Technology. All rules applying to animal safety and care were observed.

\subsection{Experimental method}

Thirty mice weighing 16- $20 \mathrm{~g}$ were randomly assigned into three groups of ten mice each. Mice in the first group were administered normal saline while animals in the other two groups received daily oral doses of bromocriptine at 2.5 and $5.0 \mathrm{mg} / \mathrm{kg}$ respectively. Body weight was measured weekly throughout the experimental period; at the end of 30 days animals were sacrificed and the liver and right kidney of each of the animal dissected out through a midline abdominal incision passing through the abdominal wall musculature into the peritoneal cavity. The organs were observed grossly and then fixed in $10 \%$ formolsaline for histological studies. Paraffin sections were cut and stained with Haematoxylin and Eosin for general histological study. The sections were examined under a Carl Zeiss microscope (Axioscope 40, Germany) with a digital camera attached.

\subsection{Determination of body weight and relative liver and kidney weights}

The body weights of the animals were measured weekly, while at sacrifice the weight of the liver and kidneys were taken. All weights were taken using a top loader sensitive balance (Mettler Toledo, Germany). Percentage weight change (gain or loss, was calculated as shown)

Final weight - initial weight

Initial weight $-\mathrm{X} 100$

\subsection{Statistical analysis}

Data from weight estimation was analyzed by one way analysis of variance (ANOVA) and post-hoc tests (Student Newman Keuls) were used to determine the source of a significant effect. Results are expressed as Mean \pm S.E.M., $\mathrm{p}<0.05$ is taken as accepted level of significant difference from control.

\section{Results}

\section{Effects of bromocriptine methanesulfonate on body weight.}

Figure 1 shows the effect of bromocriptine on the mean percent body weight change following a 30 day treatment period. There was a reduction in the mean percent body weight in animals that received bromocriptine compared to control although this difference was only visual ( $\mathrm{f}(2.18)=2.40, \mathrm{p}=.119)$.

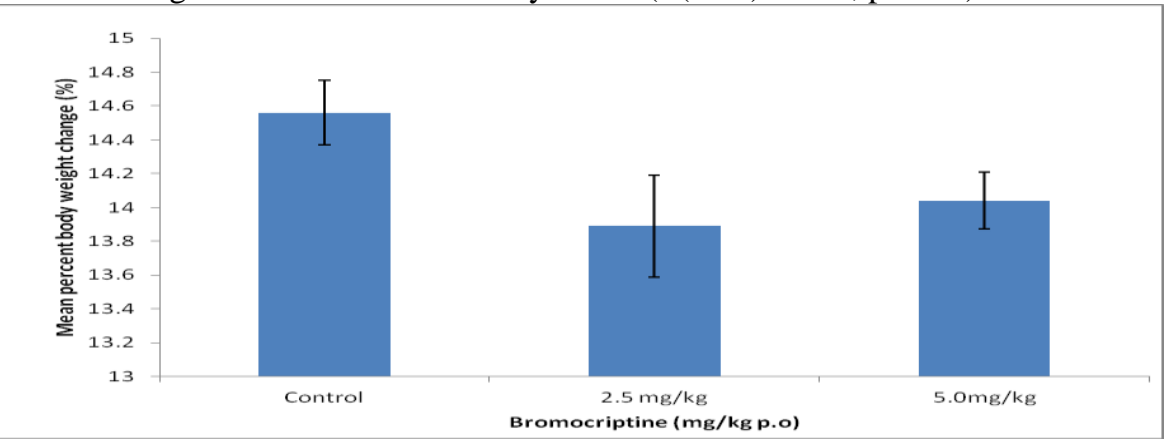

Figure 1. Effect of Bromocriptine $(2.5$ and $5.0 \mathrm{mg} / \mathrm{kg}$ ) on percentage weight change. Each bar represents Mean \pm S.E.M, ${ }^{*} \mathrm{p} \leq .05$ compared to the control, $\mathrm{n}=7$. 


\section{III.1 Effects of bromocriptine methanesulfonate on relative liver and kidney weight.}

Figure 2 shows the mean relative weights of the liver and kidney in all groups. There was a significant $(\mathrm{F}(2,18)=5.81, \mathrm{p}=.011)$ increase in kidney weight in groups that received bromocriptine compared to control, mean relative liver weight was noticed to have increased significantly $(F(2,18)=435.38, p \leq 0.05)$ in mice that received bromocriptine at $5.0 \mathrm{mg} / \mathrm{kg}$ compared to control, while at $2.5 \mathrm{mg} / \mathrm{kg}$ liver weight was slightly reduced compared to control, difference however was not statistically significant.

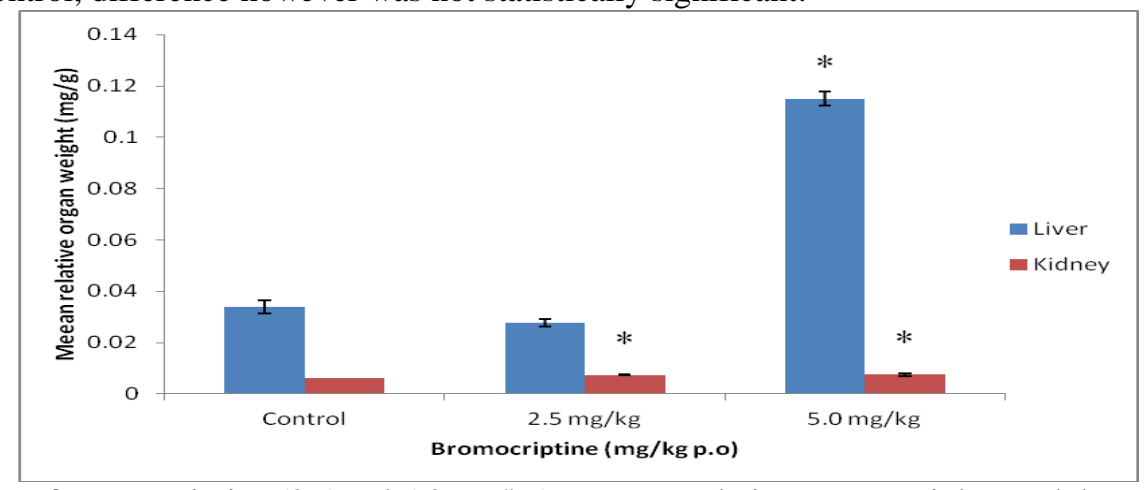

Figure 2. Effect of Bromocriptine ( 2.5 and $5.0 \mathrm{mg} / \mathrm{kg}$ ) on mean relative organ weight. Each bar represents Mean \pm S.E.M, $* \mathrm{p} \leq .05$ compared to the control, $\mathrm{n}=7$.

\section{III.2 Effect of bromocriptine methanesulfonate on liver microanatomy.}

Sections through the liver of animals in the control group (Plate 1) shows sheets of radially arranged hepatocytes with well demarcated nuclei and intervening sinusoids, normal central vein and hepatic artery, features in keeping with normal histology. Examination of sections through livers of animals that received 2.5 $\mathrm{mg} / \mathrm{kg}$ (plate 2) and $5.0 \mathrm{mg} / \mathrm{kg}$ of bromocriptine (plate 3) showed loss of liver architecture with varying degrees of liver parenchymal disorganization, dilation of the central vein and presence of inflammatory cells within and around the central vein and liver parenchyma.

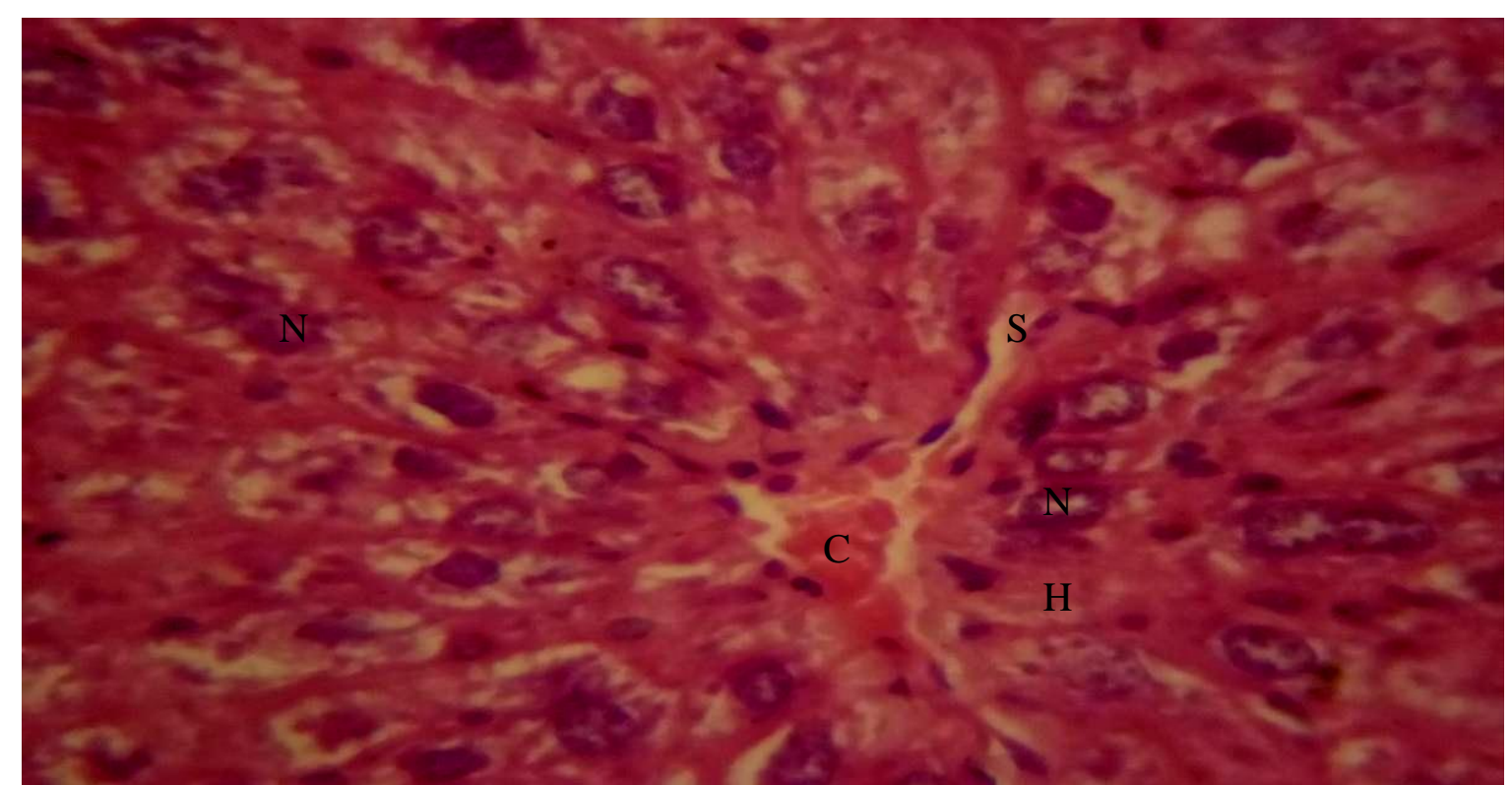

Plate 1. Photomicrograph of liver of mice in the control group showing radially arranged hepatocytes $(\mathrm{H})$ with basophilic nuclei $(\mathrm{N})$ around a central vein $(\mathrm{C})$, the hepatocytes are separated by sinusoids (S). H\&E X400 


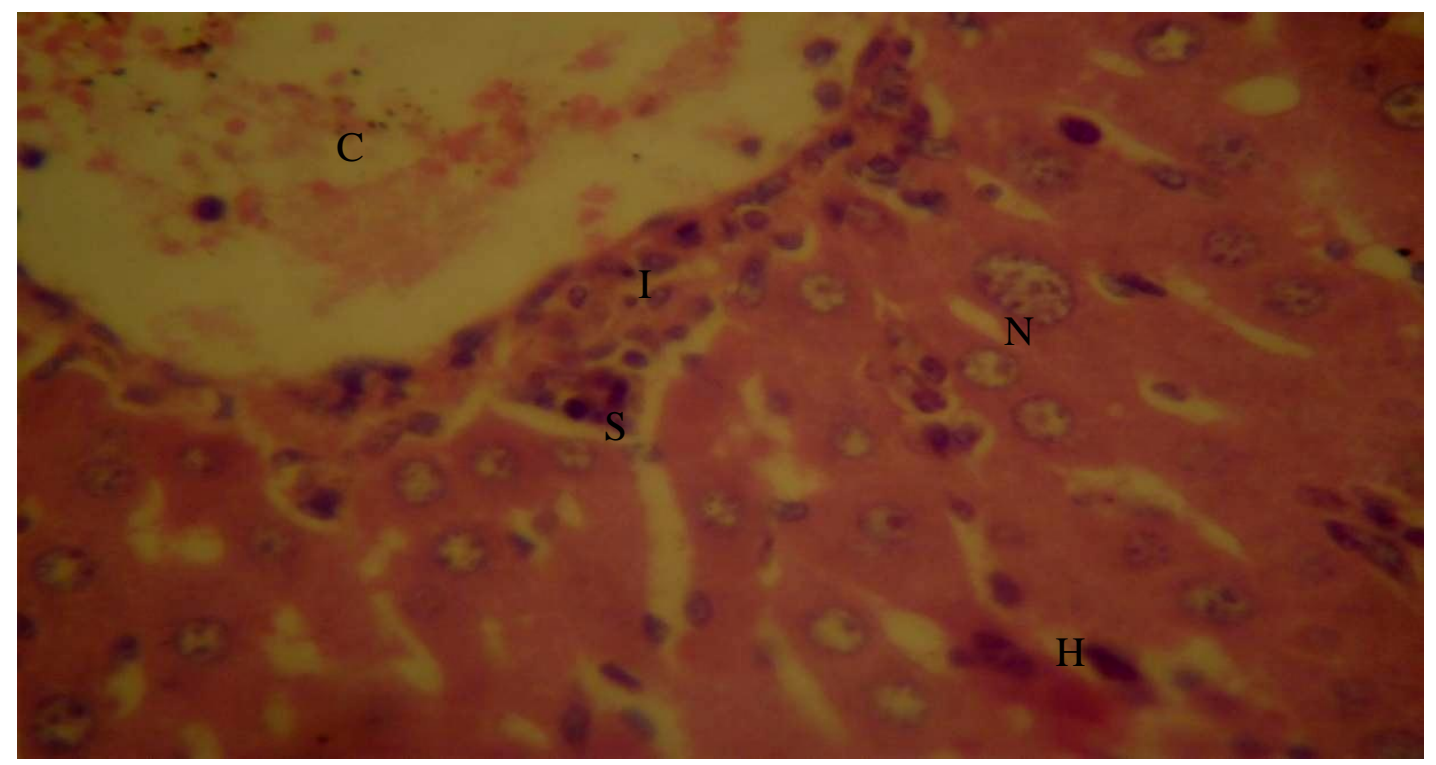

Plate 2: Photomicrograph of liver of mice that received $2.5 \mathrm{mg} / \mathrm{kg}$ of bromocriptine

showing slightly dilated central vein $(\mathrm{C})$, surrounded by shrunken hepatocytes $(\mathrm{H})$ with pale and poorly staining nuclei (N). Also, increase in inflammatory cells (I) and Kupffer cells. H\&E X400

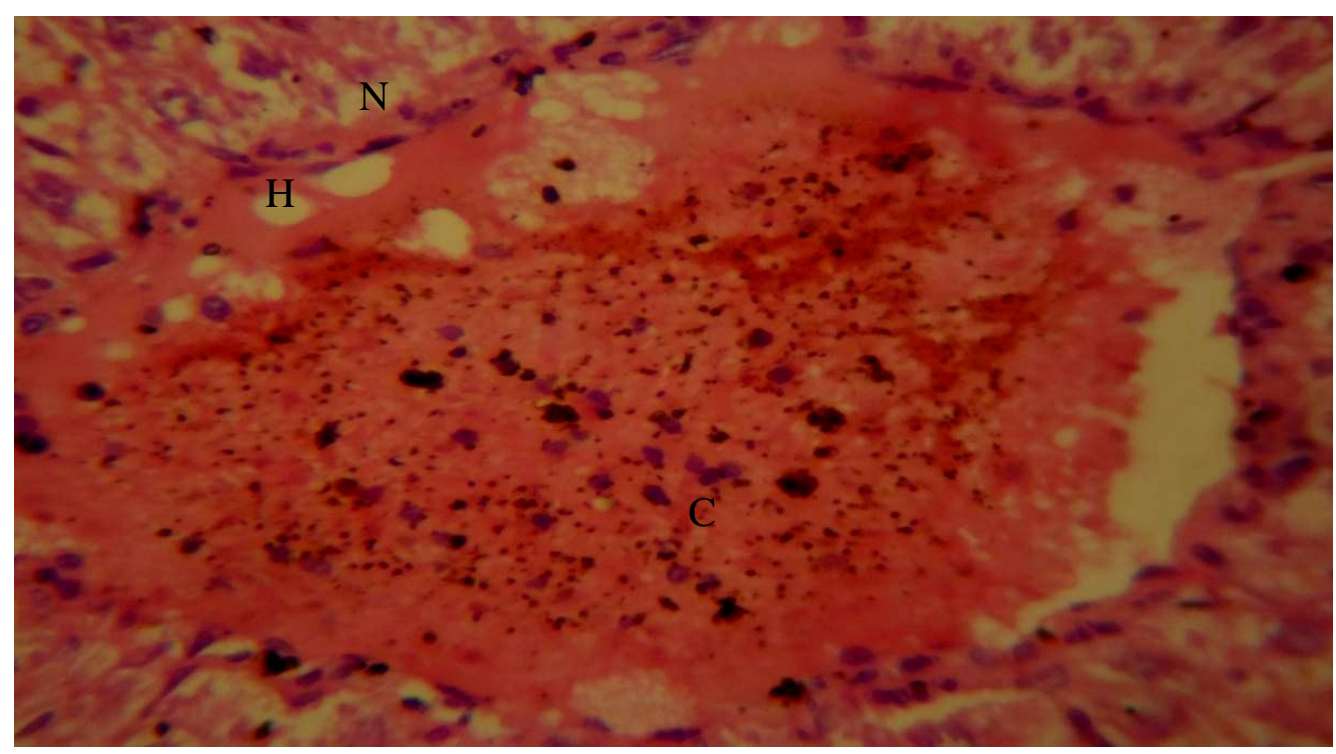

Plate 3: Photomicrograph of liver of mice that received $5.0 \mathrm{mg} / \mathrm{kg}$ of bromocriptine showing markedly dilated central vein $(\mathrm{C})$, surrounded by shrunken hepatocytes $(\mathrm{H})$ with pale and poorly staining nuclei $(\mathrm{N})$ and numerous degenerating cells and debris. H\&E X400

\section{III.3 Effect of bromocriptine methanesulfonate on kidney microanatomy.}

Slides taken from sections of the kidney of animals in the control group (Plate 1) showed well demarcated cortex and medulla, glomeruli, renal tubules, collecting ducts and blood vessels, features are in keeping with normal kidney histology. Sections from animals that received $2.5 \mathrm{mg} / \mathrm{kg}$ of bromocriptine (Plate 2) showed renal parenchyma with crumpled glomeruli within the glomerula capsule with an increase in the capsular space also seen is an increase in inflammatory cells within the renal parenchyma, animals in the third group that received bromocriptine at $5.0 \mathrm{mg} / \mathrm{kg}$ (Plate 3) showed loss of normal renal architecture and varying degrees of inflammatory cell infiltration within the glomerula and interstitium. Some of the glomeruli were distorted and slightly expanded with venous congestion. 


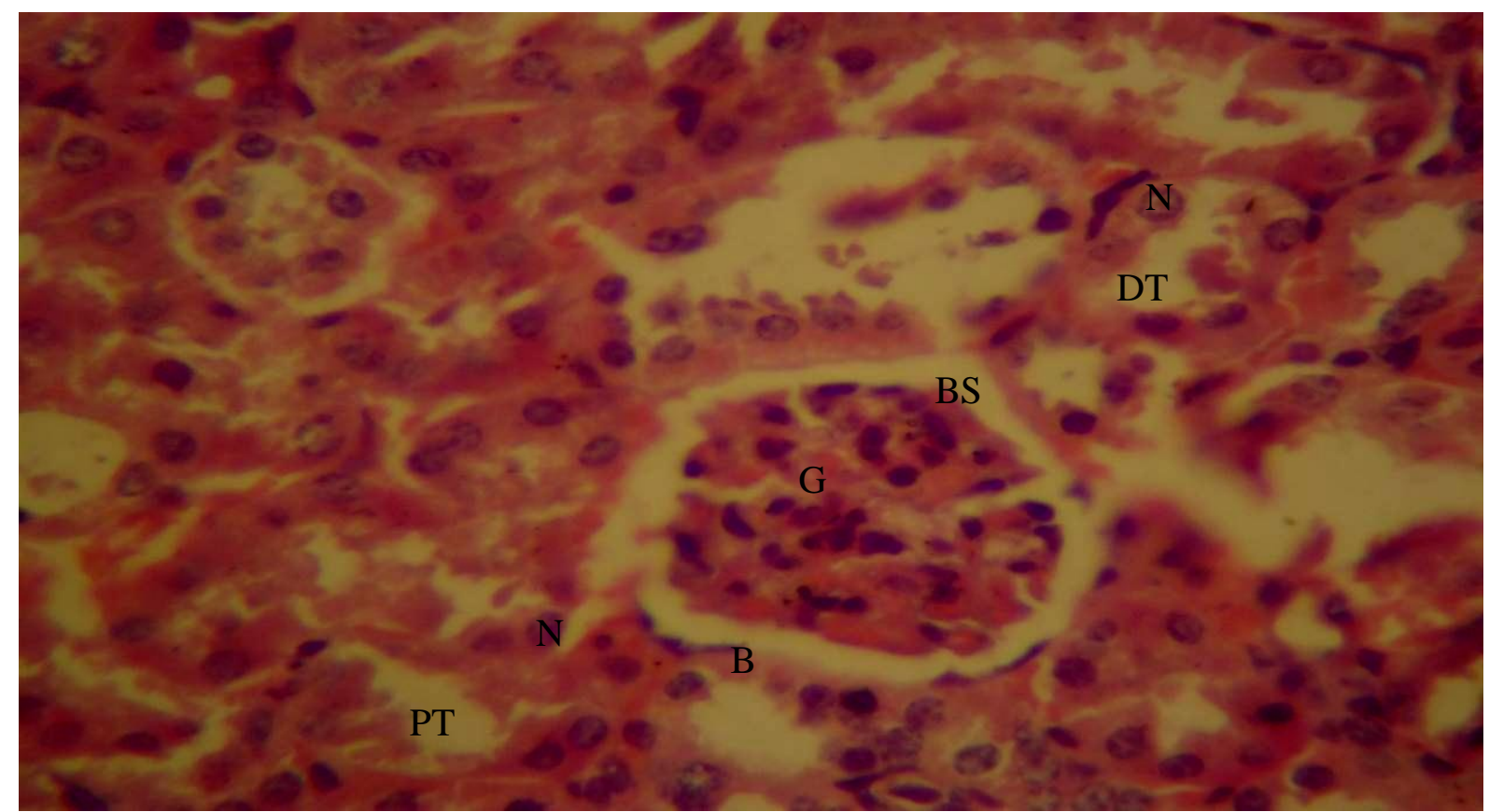

Plate 4: Photomicrograph of kidney of control group mice showing normal architecture with prominent glomeruli (G) and Bowman's capsule (B) and space (BS) with normal sized proximal (PT) and distal tubules (DT). The renal cell nuclei are prominent deeply staining with regular sizes (N) H\&E X400

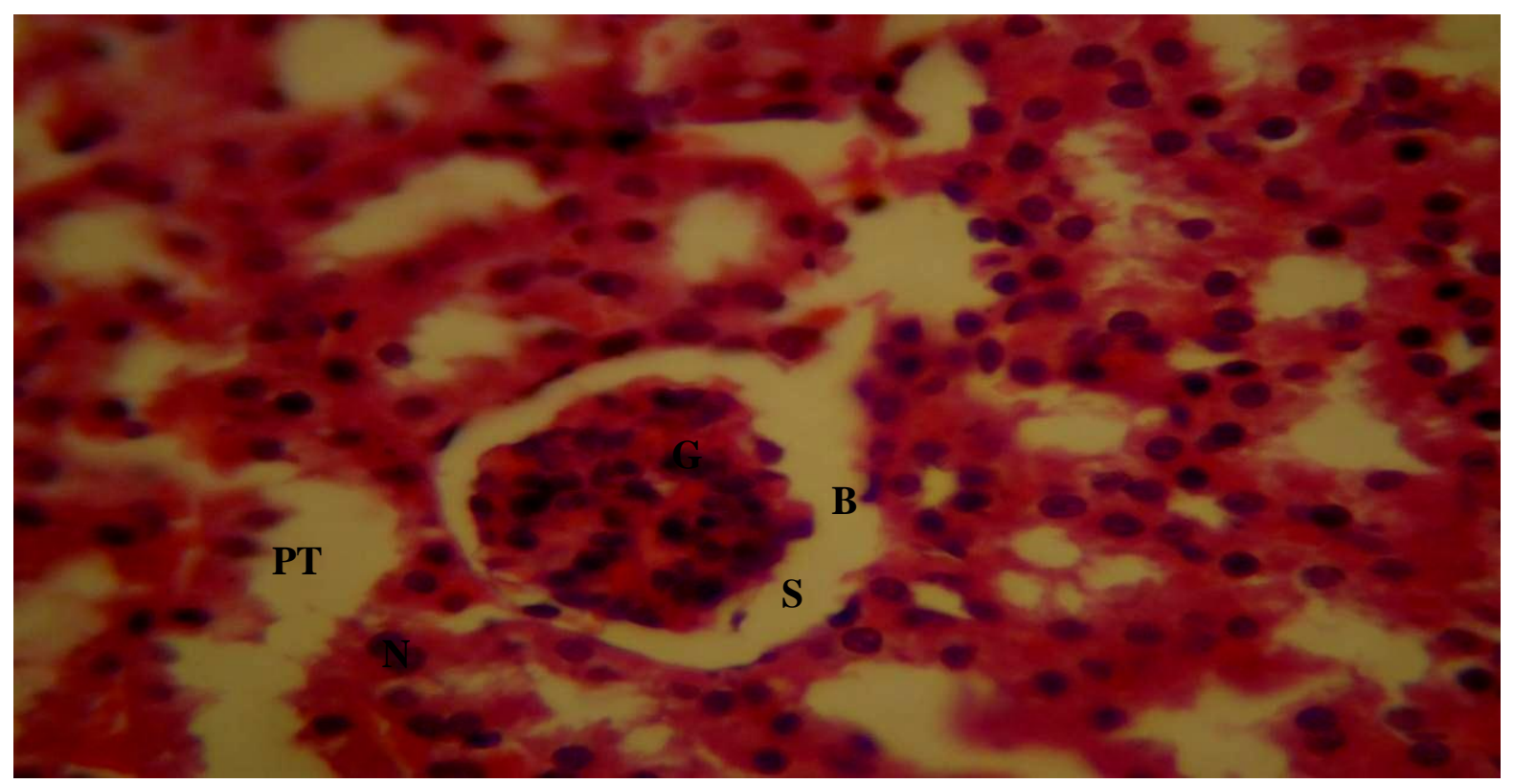

Plate 5: Photomicrograph of kidney of mice administered $2.5 \mathrm{mg} / \mathrm{kg}$ of dexamethasone showing the Bowman's capsule (B) with widening of the Bowman's space (S) from contraction of the glomerulus (G) with an increase in cellularity across the renal parenchyma, the tubules however appear normal (PT, DT). H\&E X400 


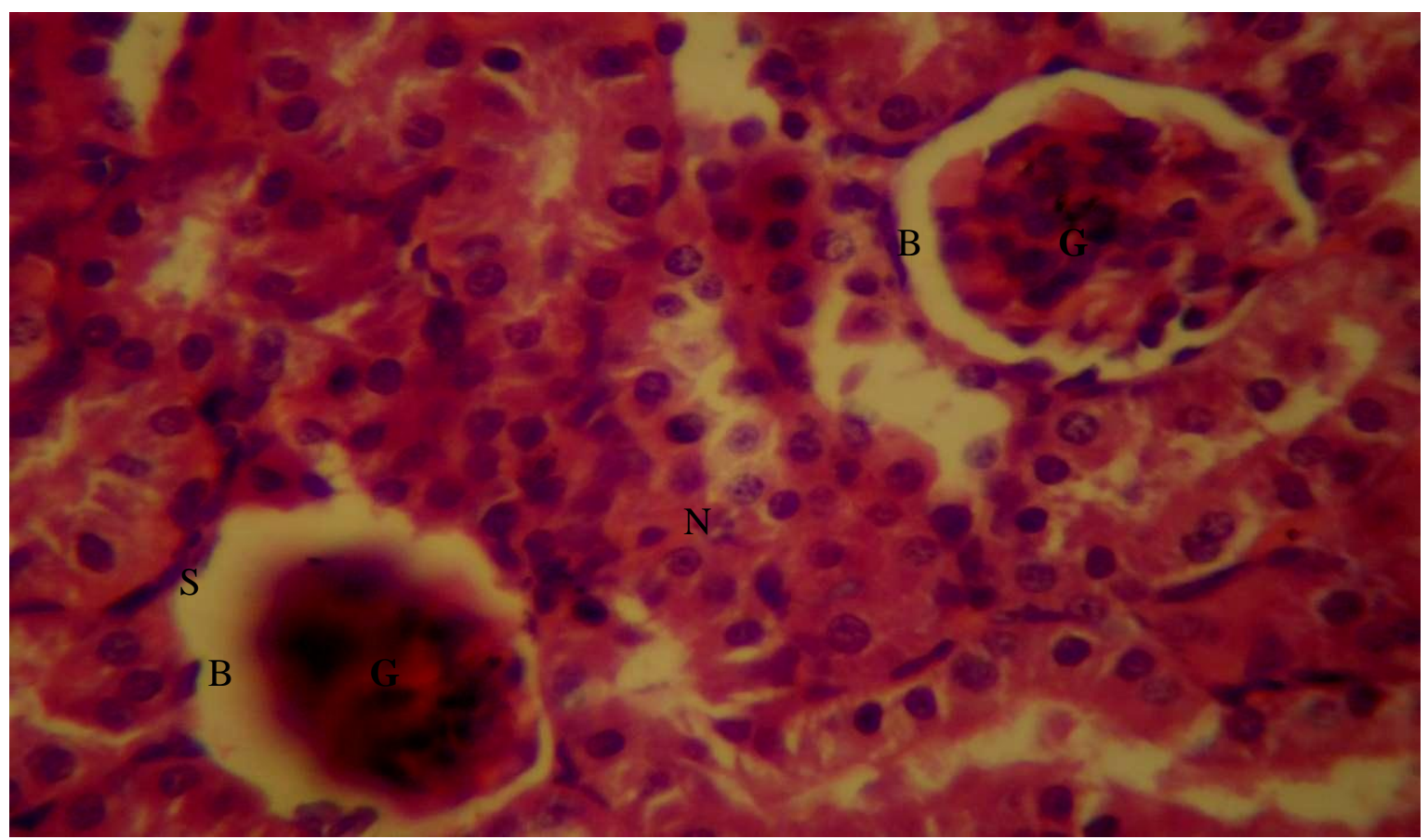

Plate 6: Photomicrograph of kidney of mice administered $5.0 \mathrm{mg} / \mathrm{kg}$ of dexamethasone showing the Bowman's capsule (B) with increase in the capsular space (S) from contraction of the glomerulus (G) and increased inflammatory cell within the glomerulus and renal parenchyma, the proximal and distal tubules appear contracted, H\&E X400.

\section{Discussion}

The present study examined the effect of bromocriptine methanesulfonate, a D2 agonist on the body weight, relative liver/ kidney weight and liver/ kidney microanatomy in healthy Swiss mice. The salient findings in this study were that bromocriptine did not significantly change the mean percent body weight but caused a dose dependent increase in mean relative liver/kidney weight and liver/kidney injury at the doses studied. Numerous studies have demonstrated that bromocriptine causes significant reductions in body weight in both animal (11-12) and human studies (13). In our study we did not observe any significant reductions in body weight following treatment with bromocriptine although marginally less weight gain was seen compared to control animals, these finding however corroborate the results of some other studies (11-12, 14-15). Bromocriptine's ability to cause a reduction in body weight has been attributed to reduction of food intake in both rodent models of obesity and normal animals. Bromocriptine has also been reported to reduce fat deposits in animals (11) and humans (13); it is able to do this partly due to its actions on hepatic triglycerides and also its actions as a dopamine agonist. Dopamine is an important regulator of the body's energy expenditure (16) and food consumption (17). Abnormalities in the signal transduction of dopamine may result in overeating and reduction in energy expenditure (18).

The incidence of drug-induced renal injury has continued to increase with the increased availability of over-the-counter medication and herbal medicines. The kidney receives a rich blood flow of $25 \%$ of resting cardiac output and plays an important role in the elimination of many drugs (bromocriptine inclusive) and their metabolites. Mean relative kidney weight increased significantly with test drug compared to control; there was also mild to moderate glomerular injury as evidenced by crumpling of the glomeruli and increase in the capsular space (Plate 5), glomerular haemorrhage and a slight increase in inflammatory cell within the insterstitum. Little, if any work has been done on the impact of bromocriptine on the kidneys, there have however been reports in humans of the development of acute renal failure within a few days of commencement of bromocriptine, symptoms of which abated with drug withdrawal (19-20), acute renal failure in these cases were attributed to either vasospasm (20) or the onset of retroperitoneal fibrosis (5), other causes such as the increased accumulation of free amino acids such as taurine and glutamic acid in the kidneys have also been considered (21).

There was a dose related increase in mean relative liver weight and liver histology showed moderate to severe dilation of the central vein and increase in inflammatory cells around the central vein; these features were more at $5.0 \mathrm{mg} / \mathrm{kg}$. Drug-induced hepatotoxicity is a common cause of disease and accounts for about one-half of the cases of acute liver failure seen (22). An estimated 1000 drugs have been implicated in liver disease (23) and with the exception of a few cases; drug-induced liver injury usually abates with drug withdrawal. 
Bromocriptine undergoes extensive first-pass bio-transformation, reflected by complex metabolite profiles and by almost complete absence of parent drug in urine and feces (24). In humans, bromocriptine has been known to cause rarely acute liver injury $(8,9)$ usually evidenced by transient asymptomatic increases in serum alkaline phosphatase and/or transaminases but not outright liver failure or liver cirrhosis (25-26), hyponatraemia has also been associated with the use of bromocriptine in patients with cirrhosis and hepatic encephalopathy (27) and for these reasons its use is not advised in the presence of prior liver disease.

\section{Conclusion}

The study concluded that at doses tested, bromocriptine has both hepatotoxic and nephrotoxic potential in mice as evidenced by test groups' histology which showed evidence of liver and kidney injury.

\section{References}

[1]. H. Pijl, S. Ohashi, M. Matsuda and Y. Myazaki Y, A Novel Approach To The Treatment Of Type-2 Diabetes, Diabetes Care Journal: 23:2000, 1154-1161.

[2]. M.L Friis, T. Johnson, N.E. Larsen, E.F. Hvidberg and H. Pakkenberg, Bromocriptine concentration in saliva and plasma after longterm treatment of patients with Parkinson's disease, European Journal of Clinical Pharmacology 18: 1980, $171-174$.

[3]. E. Katz, H.F. Schran and E.Y Adashi, Successful treatment of a prolactin-producing pituitary macroadenoma with intravaginal bromocriptine mesylate: A novel approach to intolerance of oral therapy; Journal of Obstetric and Gynecology; 73:3(2), 1989.

[4]. Flogstad, A.K., J. Halse, P. Grass, E. Abisch, O. Djoseland, K. Kutz, E. Bodd and J. Jervell (1994): “A comparison of octreotide, bromocriptine, or a combination of both drugs in acromegaly," J. Clin. Endocrinol. Metab. 79: 461-465.

[5]. Parlodel, Novartis Company Information's, 2005

[6]. L.L Brunton, D.K Blumenthal, N. Murri, R.H. Dandan and B.C Knollmann, Pituitary hormones and their hypothalamic releasing hormones, Goodman and Gilman's; the Pharmacological basis of therapeutics. 12th ed. New York: McGraw-Hill, 2011.

[7]. K. Parfitt and N. Martindale, The complete drug reference. 32nd Ed. London: The Pharmaceutical Press, 1132, 1575-6, 1999

[8]. N.L Liberato, M. Poli, P. Bollati, F. Chiofalo and M. Filipponi. Bromocriptine-induced acute hepatitis Lancet, 340(8825), 1992, 969-70

[9]. Livertox, Clinicaland research information on drug induced liver disease, U.S. National Library of Medicine, National Institutes of Health, U.S. Department of Health \& Human Services, 2013.

[10]. O.J Onaolapo and A. Y. Onaolapo, Subchronic oral bromocriptine methanesulfonate enhances open field novelty- induced behavior and spatial memory in Swiss albino mice, Neuroscience journal Volume 2013 (2013), 2012, 948241

[11]. A.H. Cincotta and A.H. Meier, Reductions of body fat stores and total plasma cholesterol and triglyceride concentrations in several species by bromocriptine treatment. Life Science, 45, 1989, 2247-2254

[12]. H. Eiscmann, D. E. Bauman, D. E. Hope and H. F. Travis, Evaluation of a role for prolactin in growth and the photoperiod-induced growth response in sheep. Journal of Animal Science. 1984, 59-86.

[13]. A.H Meier, A.H Cincotta and W.C. Lovell, Timed bromocriptine administration reduces body fat stores in obese subjects and hyperglycemia in type II diabetics. Experientia, 48: 1992, 248-253.

[14]. L. M. Davis, M. Michaelides, L. J Cheskin, T. H Moran, S. Aja, P. A Watkins, Zh. Pei, et al., Bromocriptine administration reduces hyperphagia and adiposity and differentially affects dopamine $\mathrm{d} 2$ receptor and transporter binding in leptin-receptor-deficient Zucker rats and rats with diet-induced obesity, Neuroendocrinology 2008; DOI: 10.1159/000170586

[15]. J.L.L. Southern, A, H . Cincotta, A. H. Meier, T. D. Bidner and K. L. Watkin Bromocriptine-induced reduction of body fat in pigs, Journal of Animal Science, 68, 1990, 931-936

[16]. D.K. Ingram, G.S. Roth, H. Umegaki, H. Ikari, Development of an adenoviral vector for intracerebral delivery of the dopamine D 2 receptor. Mech Ageing Dev, 116: 2000, 77-93.

[17]. K.G. Bina and A.H Cincotta, Dopaminergic agonists normalize elevated hypothalamic neuropeptide Y and corticotropin-releasing hormone, body weight gain, and hyperglycemia in ob/ob mice. Neuroendocrinology, 71, 2000, 68-78

[18]. W. Schultz, Getting formal with dopamine and reward. Neuron, 36: 2002, 241-263.

[19]. B. Barroso, P. Bigou, K. Martin, A. Lippa, L. Chabouni, A. Dakar, E. and J.M, Larrieu Reversible postpartum cerebral angiopathy associated with bromocriptine therapy; Rev Neurol (Paris), 160 (12), 2004, 1191-3.

[20]. R. Makdassi, B. de Cagny, E. Lobjoie, M. Andrejak and A. Fournier, Convulsion hypertension crises and acute renal failure in the postpartum: The role of bromocriptine? Nephron, 72, 1996, 732-733

[21]. A. Abdulrahman, M. Ageel, K. E.H. El Tahir and Abdulrahim Abu-Jayyab Influence of bromocriptine on free amino acids in the kidneys and heart of the rat Bio Pharmacol. Vol. 36(24), 1987, 4293-4295

[22]. Kaplowitz, Drug-induced liver disorders: implications for drug development and regulation. Drug Safety;24:2000, 483-90

[23]. H. Zimmerman, Hepatotoxicity: the adverse effects of drugs and other chemicals on the liver. 2nd ed. Philadelphia: Lippincott, Williams \& Wilkins; 1999.

[24]. H.F Schran, S.I. Bhuta, P. Schwartz, The pharmacokinetics of Bromocriptine in man. Ergot compound and brain function: Neuroendocrine and neuropsychiatric aspects, In: Golstein, M. Calne, D.B.,et. Al (eds). pp. 125-139, New York, Rave Press, 1980.

[25]. D.G Kissner and J.C Jarret, Side effects of bromocriptine. N Engl J Med 302, 1980, 749-75.

[26]. J. Webster, A comparative review of the tolerability profiles of dopamine agonists in the treatment of hyperprolactinaemia and inhibition of lactation. Drug Safety, 14, 1986, 228-238.

[27]. A.W Marshall, A.W Jakobovitz and M.Y Morgan, Bromocriptine associated hyponatriaemia in cirrhosis. Br Med J (Clin Res Ed) 28, 1982, 1534-1535. 